\title{
The Impact of Trauma-Based Training on Educators
}

\author{
Jennifer Parker ${ }^{1} \cdot$ Stacey Olson ${ }^{1} \cdot$ James Bunde ${ }^{2}$
}

Published online: 15 May 2019

(C) Springer Nature Switzerland AG 2019

\begin{abstract}
An extensive literature establishing the prevalence of Adverse Childhood Experiences (ACEs) and their destructive impact over the lifespan has motivated recent efforts to fundamentally alter the educational milieu. One such initiative, entitled "Compassionate Schools," involves the training of educators in trauma-informed and trauma-sensitive practices, in the hopes of creating scholastic environments more conducive to widespread resilience. Despite encouraging initial reports, few studies have empirically evaluated the impact of Compassionate Schools training on attendees. The current investigation reports the results of two studies. In Study 1, participants completed a questionnaire 6 months after their Compassionate Schools trainings, including items relevant to mindset and behavior change. In Study 2, participants completed the Attitudes Relevant to Trauma Informed Care (ARTIC) scale before and after a Compassionate Schools training. The majority of participants in Study 1 reported enduring changes in mindset and behavior as a result of their trainings, and described those changes in terms consistent with the Compassionate Schools model. ARTIC responses in Study 2 suggested marked trauma-informed attitudinal improvements between pre- and post-training assessments. These data, although preliminary, are consistent with the Compassionate Schools paradigm, and empirically support its promise as a ACEs-informed intervention for educators.
\end{abstract}

Keywords Compassionate schools $\cdot$ Resiliency $\cdot$ Trauma-informed $\cdot$ Trauma sensitive

Childhood adversity involves early exposure to various forms of abuse (i.e., psychological, physical, and sexual), household dysfunction (e.g., substance abuse, mental illness, domestic violence, criminality), and problematic social-contextual stress (e.g., community or school violence). These "Adverse Childhood Experiences" (ACEs) have been the subject of significant scholarly attention in recent decades (for a review, see Kalmakis and Chandler 2015). Despite marked conceptual ambiguity and varying operational definitions (Kalmakis and Chandler 2014), several general findings emerge from the extant literature.

First, ACEs are disconcertingly common, with a high percentage of children experiencing at least one potentially traumatic event before reaching adolescence and many exposed to

Jennifer Parker

jparker@uscupstate.edu

1 Child Protection Training Center, University of South Carolina Upstate, 160 E. St. John Street, Spartanburg, SC 29306, USA

2 Psychology Department, University of South Carolina Upstate, Spartanburg, SC, USA multiple, varied sources of adversity (Felitti et al. 1998; McLaughlin et al. 2013). Second, ACEs are associated with significant negative outcomes later in life. Informed by research linking specific forms of early maltreatment to problematic development, the original ACE study (Felitti et al. 1998) revealed powerful, graded relationships between the number of categories of ACE exposure and a host of psychological and physical difficulties in adulthood (for a review of this literature, see Felitti and Anda 2010). Third, trauma and adversity are linked to concurrent problems in emotional, cognitive, and social development, and are associated with an array of behavioral and psychological difficulties in children and adolescents (Bosquet Enlow et al. 2012; Chan and Yeung 2009; Clark et al. 2010; Copeland et al. 2007; Ford et al. 2010; Kilpatrick et al. 2000; McLaughlin et al. 2013; Ruchkin et al. 2007; Stallard 2006). ACEs, particularly if repeated or sustained, are associated with impaired attention, memory, and concentration, as well as difficulties with emotional regulation, healthy attachment, communication, and impulse control (Cook et al. 2005; Shipman et al. 2005, 2000).

It is unsurprising, therefore, that ACEs are also predictive of academic difficulties, conduct problems, and delinquency, and that traumatized students are at increased risk for 
suspension and expulsion, poor attendance, risky behaviors, low self-esteem, and disengagement (Delaney-Black et al. 2002; Ford et al. 2010; Greenwald 2002; Grogger 1997; Ko et al. 2008; Kilpatrick et al. 2000; Luke and Coyne 2008; Hurt et al. 2001; Shonk and Cicchetti 2001). Given the challenges they face, it would appear unreasonable to expect such students to behave, react, and perform typically in a standard classroom. Indeed, many traditional scholastic expectations and practices (e.g., punitive responses to problematic behavior) represent unnecessary, counterproductive, and potentially insurmountable obstacles to their success (see Cole et al. 2005 , for a review and extended discussion of the difficulties traumatized children routinely face in the academic mileau).

The Compassionate Schools (CS) initiative, inaugurated in Washington State in 2008 (Hertel et al. 2009), was developed in response to the general body of evidence reviewed above. The program is intended to foster cultural and environmental conditions conducive to healthy development for all children (including those who have experienced adversity). Within the CS theoretical framework, school-wide improvement should result from 1) familiarizing educators with the ACEs literature, 2) instructing them in effective, trauma-sensitive practices, 3) encouraging personal self-care and awareness, and 4) amplifying student, family, and community engagement with the educational system. Practices are deemed "traumasensitive" if they promote healthy, caring, and supportive interactions among students and educators. Such interactions should, from the CS perspective, allow schools to capitalize on the constellation of benefits accompanying nurturant relationships in traumatized youth (e.g., increases in resilience, executive functioning, self-regulation, general health, and interpersonal competence). The model prioritizes student empowerment, and emphasizes the maintanence of high standards of conduct and performance.

The results from the Washington State Compassionate Schools initiative are promising (Hertel et al. 2009), and similar trainings are now available at a number of U.S. sites. Few studies to date, however, have systematically examined the feasibility of such programs or their impact on educators and the students they serve. The current investigation attempts to contribute to this literature by evaluating the perceived impact of Compassionate Schools training among attendees of the Child Protection Training Center (CPTC) at the University of South Carolina Upstate.

In Study 1, a survey was constructed by the research team and delivered to Compassionate Schools attendees six months after their trainings, to examine perceptions of the nature and durability of impact. In Study 2, participants were assessed before and after their Compassionate Schools trainings using a reliable and valid measure of trauma-informed attitudes. As the current set of studies is preliminary, and the 1st largely exploratory, randomization to control groups was deemed premature and inappropriate. In Study 1, we were simply hoping to investigate the responses of educators assigned to receive the training, and to explore whether these responses were consistent with the Compassionate Schools model and the content of the sessions. For this purpose, a single-group, retrospective design was selected. As we were hoping to assess the perceived impact of the training and impressions thereof, as opposed to changes in absolute levels of knowledge, attitudes, or behaviors, pre-training questions were deemed inappropriate. A retrospective pre-post design was also rejected, given its inapplicability to many of our key study questions. Study 2 was conducted to build on the exploratory results of Study 1, using a stronger methodology and a psychometrically-established instrument. Thus, participant responses to Compassionate Schools were assessed using a pre- and post-training administration of a reliable and valid measure of trauma-informed attitudes.

\section{CPTC Compassionate Schools Training}

The CPTC launched a Compassionate Schools initiative in Spartanburg, SC, in 2016. The Compassionate Schools paradigm (see Cole et al. 2005; Hertel et al. 2009) is a flexible, generalized framework built on the science of ACEs and toxic stress. Embracing an ecological systems perspective (Bronfenbrenner 1979), its goal is to improve educational and behavioral outcomes by cultivating a trauma-sensitive and trauma-informed learning environment. The phrase "trauma-informed," from a Compassionate Schools perspective, does not refer to the identification of individual children who have been traumatized (although this is certainly important), but to an approach that assumes a high prevalence of such experiences and is consequently designed to foster resilience for all students. According to the Children's Trust of South Carolina, ACEs are in fact quite common in the state: $62 \%$ of adults reported at least one adverse childhood event in 2016 , with $22 \%$ reporting two or more and $16 \%$ reporting four or more (https://scchildren.org/research/resources/).

In January 2016, a steering committee of superintendents, principals, school social workers, educators, and community leaders was established to discuss the feasibility of implementing a trauma-informed framework in Spartanburg County schools. Utilizing the general Compassionate Schools paradigm (Wolpow et al. 2009), the CPTC developed a flexible community-training model tailored to the specific, individual needs of schools and community agencies in the Spartanburg area. The overarching goals were: 1) to create widespread awareness, in the schools and broader community, of the prevalence and impact of trauma, and 2) to train relevant personnel in appropriate strategies for responding to trauma, fostering resilience, and preventing re-traumatization. Programming was informed by a review of the relevant 
literature on ACEs and Compassionate Schools, consultation with personnel from other Compassionate Schools initiatives (as well local and national experts on child advocacy), an informal but extensive community assessment of Spartanburg and the surrounding area, and communication with local school and school district representatives regarding their individual circumstances, challenges, limitations, and concerns. Trainings were planned and organized by the CPTC, and were executed by CPTC staff and a team of local experts (e.g., 3 Master ACE trainers, pediatricians, forensic interviewers, SLED (South Carolina Law Enforcement Division) officers, community organizers).

Participants in the current studies attended either a half-day or 3-day Compassionate Schools training at the CPTC. All trainees encountered the following elements: 1) an introduction to the Compassionate Schools framework, 2) standardized education in the ACEs literature (e.g., prevalence, lifelong risks, neurodevelopment, intergenerational transmission, community impact), 3) a simulation of ACEs in a staged mock house, 4) training in recognizing signs of abuse and neglect, and 5) education on social/emotional learning and resilience skills. The three-day trainings included the following components in addition: 1) a screening and panel discussion of the documentary "Paper Tigers" (http://papertigersmovie.com/), a film exploring the impact of ACEs on the lives of students and staff at a particular school, 2) training in cultural sensitivity, 3) a presentation on mandatory reporting, and 4) education in healthy boundaries, practices, and self-care for professionals (see Appendix 1 for additional information; further inquiries regarding the specific content of CPTC trainings should be directed to the corresponding author).

\section{Study 1 Method}

\section{Procedure}

In Study 1, potential participants had attended either a halfday or 3-day Compassionate Schools session (funded by a Spartanburg County Behavioral Health Taskforce initiative) in 2016. Eligible educators were recruited via email approximately 6 months after the completion of their trainings (unfortunately, technical difficulties make calculation of a precise response rate impossible - the research team was informed months later that many potential participants did not in fact receive the recruitment message due to email filtering).

After completing a series of demographic items, participants were asked to respond to the following: 1a) Have you experienced a change in your thinking or mindset following Compassionate Schools training? (Yes/No), 1b) If yes, please describe; 2a) Have you made any changes (in behavior, practice, or procedure) in response to your Compassionate Schools training? (Yes/No), 2b) If yes, please describe; 3) What are the most important things you learned in your Compassionate Schools training (if any)?; 4) Which aspects of Compassionate Schools would you like to see implemented at your school?; 4a) If there are barriers to implementation, please describe; and 5) What suggestions do you have for improving the training?

The dichotomous items (i.e., did you (yes/no) experience changes in your mindset/behavior?) were intended to capture the perception of some kind of durable impact, and the narrative items to illuminate this perception. For example, six months after their trainings, did participants describe persistent attitudinal, behavioral, and educational change consistent with the Compassionate Schools framework? After returning to work for a significant period, how did they currently feel about the need for implementation, support for implementation, and the training as a whole? Thematic categories were developed after an exhaustive review of the narrative data. Each response was then coded by two independent raters, and instances of disagreement were adjudicated by a third rater.

\section{Participants}

Of the 133 participants, $73(55 \%)$ attended a half-day session, and $60(n=45 \%)$ attended a 3 -day training. The majority were women $(n=106,80 \%)$, and either African-American $(n=31$, $23 \%)$ or Caucasian $(n=98,74 \%)$. Elementary $(n=45,34 \%)$, Middle $(n=36,27 \%)$, and High School $(n=16,12 \%)$ educators were prominently represented, as were teachers $(n=45$, $34 \%)$, behavioral professionals $(n=35,26 \%)$, and principals $(n=28,21 \%)$. The majority $(\mathrm{n}=98,74 \%)$ of respondents reported more than 10 years of experience in their current roles.

\section{Study 1 Results}

The majority of participants reported changes in mindset $(n=$ $114,86 \%)$ and behavior $(n=101,76 \%)$ in response to their Compassionate Schools trainings, with 98 (74\%) participants reporting both changes, and $16(12 \%)$ reporting neither. Responses to both change items were unrelated $(p s>.10)$ to the type of training attended, all demographic variables, and all vocational variables (i.e., program, position, years of experience).

With respect to the narrative items, it should be noted that participants were free to respond however they desired to all inquiries. Consequently, responses varied widely in length, complexity, and responsorial tone/approach (e.g., some responses were not directly relevant to the question that was asked or fell in multiple categories, and some participants responded similarly to multiple items). The data reflect percentages of valid responses only and do not necessarily add to 100 , and several categories are repeated across items. For examples of representative responses, see Appendix 2. 
Narrative Item 1: "Have you experienced a change in your thinking or mindset following Compassionate Schools training? (Yes/No) If yes, please describe"

When describing changes in thinking/mindset, responses fell into the following categories: Knowledge/Cognitive Change (57\%), Emotional Change (21\%), Behavioral Change (34\%), and Need for Dissemination (11\%).

Narrative Item 2: "Have you made any changes (in behavior, practice, or procedure) in response to your Compassionate Schools training? (Yes/No) If yes, please describe"

Descriptions of behavioral change were distributed in the following fashion: Relationship Building Behaviors (5\%), Changes in Practice (64\%), Language Changes (3\%), Emotional Changes (12\%), Knowledge/Cognitive Changes (23\%), and Changes in Awareness (40\%).

Narrative Item 3: "What are the most important things you learned in your Compassionate Schools training (if any)?"

When describing the most important things they learned, participant responses were classified as follows: Warning Signs of Maltreatment (21\%), Trauma-Informed Skills (19\%), Resilience and Relationships (15\%), ACEs/Trauma Impact (71\%), and Available Resources (7\%).

Narrative Item 4: "Which aspects of Compassionate Schools would you like to see implemented at your school?"

The following were listed as implementational desiderata: Parental Involvement (6\%), School/District-Wide Education (33\%), Experiential Training (30\%), Disciplinary Changes (3\%), Resilience Building (7\%), Already Implemented (10\%), All (the entire training) (6\%), and Other (4\%).

Narrative Item 5: "If there are barriers to implementation, please describe"

Notably, only 21 participants (16\% of the overall sample) reported barriers to implementation. These included: Time (38\%), Money (10\%), Culture (19\%), Support/Buy-In (38\%), and Other (10\%).

Narrative Item 6: "What suggestions do you have for improving the training?"

Suggestions for improving the trainings included: None (27\%), General Positivity (e.g., "Keep it up!") (32\%),
Dissemination (24\%), Follow-up Trainings (2\%), Technical Suggestions (14\%), More Practical Applications (17\%).

\section{Study 1 Discussion}

Results from the dichotomous items in Study 1 suggest that the majority of Compassionate Schools attendees perceived lasting changes in thinking and behavior as a result of their trainings at the CPTC. Further, it seems plausible that a significant subset of those who reported no such changes were not necessarily antagonistic toward the Compassionate Schools model in general or their trainings in particular, but were simply already aware of and largely accepting of the paradigm (note that $10 \%$ of respondents indicated that Compassionate Schools was already implemented at their schools). Consequently, it is possible that negative responses did not always reflect a rejection of traumainformed education, or a failure of the training to communicate the model effectively and persuasively, but to the belief among some participants that their thinking and behavior was already consistent with Compassionate Schools and consequently in no need of alteration.

Narrative responses were also broadly supportive of the model. First, when asked to provide suggestions for improving the training, a majority of respondents either 1) opined that the trainings should not be changed, 2) indicated that trainings should be offered to an increasing number of people and/or at repeated intervals, or 3) took the opportunity to congratulate the CPTC team on the work being done at the center. This represents preliminary but supportive evidence of the acceptability of the trainings and of their generally positive reception. Second, narrative responses suggested that participants characterized the effects of training in a manner consistent with the Compassionate Schools paradigm. As described above, CPTC trainings are designed to alter mindset and behavior by providing information and training on ACEs, resilience, and trauma-informed practice. The general pattern of narrative responses suggests that not only did participants perceive some lasting impact from their trainings, but that this impact (by their own description) was to in effect make them increasingly "trauma informed." The major limitations of Study 1 include the inability to calculate an accurate response rate, a sample of convenience (educators were selected for training attendance by their respective institutions - not by the research team), and a single-group, retrospective design.

\section{Study 2 Method}

Despite widespread acceptance of the prevalence and impact of ACEs, and the proliferation of rhetoric encouraging traumainformed practice in schools, few published studies to date have used a reliable and valid instrument to demonstrate attitudinal 
change following school-based, trauma-informed education. Study 2 is an effort to contribute to that literature.

\section{Procedure}

Eligible trainees attended one of three CPTC Compassionate Schools sessions during the summer of 2018. Participants completed a series of demographic items, as well as the 35item version of the Attitudes Related to Trauma Informed Care scale (ARTIC), prior to their trainings. All participants then attended a 3-day Compassionate Schools session, after which they again completed the ARTIC.

\section{Measures}

The Attitudes Related to Trauma Informed Care Scale (ARTIC) The ARTIC (Baker et al. 2016) is one of the only empirical, psychometrically acceptable measures of trauma-informed attitudes in service providers. It includes a series of self-reported, Likert-style items (scaled from 1 to 7) designed to assess a respondent's beliefs surrounding ACEs and trauma. In addition to an overall score capturing a general level of trauma sensitivity, the 35-item version of the ARTIC (employed in this study) includes the following subscales reflecting various dimensions of the broader construct: 1) underlying causes of problem behaviors and symptoms, 2) responses to problem behavior and symptoms, 3) on-the-job behavior, 4) self-efficacy at work, and 5 ) reactions to the work. Data describing the construction of the ARTIC, and supporting its reliability and validity, are presented by Baker and colleagues (Baker et al. 2016). In the current study, internal consistencies $(\alpha \mathrm{s})$ for the general scale were .92 (pre) and .94 (post), with subscale values ranging from .69-.76 (pre) and .77-.81 (post), respectively.

\section{Participants}

Participants included 219 school district employees who completed a 3-day Compassionate Schools training at the CPTC. The majority of participants were women $(n=169,74 \%)$, and either African-American $(n=57,25 \%)$ or Caucasian $(n=156$, $68 \%)$. Elementary $(n=132,58 \%)$, Middle $(n=30,13 \%)$, and High School $(n=23,10 \%)$ educators were prominently represented, as were teachers $(n=75,33 \%)$, behavioral professionals $(n=38,17 \%)$, and principals $(n=48,21 \%)$. Participants had been working in their current roles for an average of 7.3 years at the time of the study $(S D=7.84, M d n=4)$.

\section{Study 2 Results}

A number of participants failed to complete both ARTIC assessments, or inaccurately recorded their identification number (randomly and confidentially assigned to connect pre-training to post-training assessments) on one or both surveys and were consequently excluded from subsequent analyses. The results presented below were conducted on the remaining 191 participants - those who completed the ARTIC at both time points and whose pre- and post-training assessments could be statistically linked (and therefore analyzed dependently).

A series of paired-samples t-tests were conducted to examine pre- to post-training differences for the ARTIC scale and subscales. As shown in Table 1, statistically significant differences were found for each scale, representing large (with one narrow exception) pre-post effects (i.e., Cohen's $d>.80$ ). Each difference reflected an improvement in traumainformed attitudes following training, despite the fact that all pre-treatment means were above the midpoint of their respective scales (i.e., even though participants were generally endorsing trauma-informed attitudes from the outset, leaving relatively little room for improvement).

To explore the general possibility of differential impact across demographic variables, pre-post difference scores were calculated for all ARTIC scales and analyzed with respect to demographic and vocational variables (i.e., gender, race, program, position, years of experience). No significant relationships were found (all $p s>.05$ ).

\section{Study 2 Discussion}

The results of Study 2 provide empirical evidence of attitudinal change following Compassionate Schools training. Despite relatively high initial scores (compared to scale midpoints), participants still showed large improvements (i.e., increases in the degree to which they endorsed trauma-informed attitudes) on the overall scale and all subscales following their 3-day sessions. Indeed, at the post-training assessment, the means for the overall ARTIC scale and several subscales were above 6 . Given that 7 is the upper limit for these scales, this suggests that many participants not only "improved" over the course of the study, but were consistently endorsing attitudes toward the extreme end of the "trauma-informed" pole after undergoing Compassionate Schools training.

\section{Discussion}

Despite the wealth of evidence establishing the prevalence and undesirable correlates of ACEs, and the growing number of Compassionate Schools programs endeavoring to address the effects of childhood trauma, relatively few investigations have attempted to demonstrate empirically the benefits of relevant training for educators. In the current studies we used two diverse samples of CPTC trainees to evaluate this question of impact. In Study 1, the majority of participants reported enduring changes in mindset and behavior 6 months after their 
Table 1 Pre-post ARTIC analyses

\begin{tabular}{|c|c|c|c|c|c|c|}
\hline & Pre-Training: $\mathrm{M}(\mathrm{SD})^{*}$ & Post-Training: M (SD)* & $\mathrm{t}$ & df & Sig (2 -tailed $)$ & $\mathrm{d}$ \\
\hline Overall & $5.37(.63)$ & $6.04(.67)$ & -18.53 & 190 & .000 & -1.34 \\
\hline Cause & $5.10(.69)$ & $5.86(.82)$ & -14.19 & 190 & .000 & -1.03 \\
\hline Responses & $5.20(.81)$ & $5.93(.85)$ & -15.22 & 190 & .000 & -1.10 \\
\hline Job Behavior & $5.37(.74)$ & $6.07(.73)$ & -15.47 & 190 & .000 & -1.12 \\
\hline Self-Efficacy & $5.67(.79)$ & $6.16(.73)$ & -10.97 & 190 & .000 & -.79 \\
\hline Reactions & $5.50(.80)$ & $6.18(.73)$ & -15.45 & 190 & .000 & -1.12 \\
\hline
\end{tabular}

*ARTIC scale and subscale scores reflect the average of all included items (i.e., the range of possible values for each scale is 1-7)

trainings, and described these changes in a manner consistent with the Compassionate Schools model and the content of the trainings themselves. In Study 2, the ARTIC, which is one of the only reliable and valid measure of trauma-informed attitudes in existence, was employed in an interventional context. Participants exhibited generally large and universally significant improvements in relevant attitudes across the overall scale and all subscales following their trainings. Supplementary analyses suggested that these changes were observed independent of participant characteristics (e.g., gender, race, program, position, and years of experience).

\section{Limitations}

Although these results appear broadly supportive of the Compassionate Schools training model, a number of important limitations should be noted. First, all participants were nearby educators who agreed to attend a training entitled "Compassionate Schools" at a locally active training center which makes no secret of its perspective, values, and goals. They then took time out of their lives to complete a survey 6 months after the fact, to no personal material benefit. It is possible that these individuals are fundamentally different from other educators in the area, who may be less enthusiastic about attending such a training and less receptive to the ideas presented therein (this makes the unavailability of a reliable response rate all the more regrettable). This possibility is further suggested by high pre-training scores on the ARTIC in Study 2, the representativeness of which are entirely unknown. Whether Compassionate Schools trainings can fundamentally change the mindset and behavior of initially unsympathetic trainees is an important question for future studies (and something to consider when designing recruitment procedures), as is establishing baseline levels of trauma-informed attitudes among local, regional, and national populations of educators.

Second, all items in Study 1 (and many in Study 2) are inarguably face valid. That is, any attentive participant could generate clear ideas about what the "right" answer(s) to these questions might be, and may (in some cases) know how she is "supposed" to respond even prior to attending the training (when asked if Compassionate Schools changed one's behavior or mindset, the expectation is obviously in the affirmative). The trainings are, after all, intentionally clear about what constitutes a trauma-informed approach, so our questions could be conceptualized as a simple test of whether participants learned and retained enough information to provide these "correct" responses. As childhood trauma is an issue fraught with moral significance, the possibility of socially desirable responding also seems inordinately high. Still, given the subject matter, knowledge of the "right" answers and a sense that one is obligated to provide them are not insignificant matters. Given that a significant proportion of Compassionate Schools is in fact educational, they instead constitute important (albeit limited) evidence of the effectiveness and impact of the trainings. Interestingly, the average inter-item correlation for the ARTIC increased between pre-training (.24) and posttraining (.35) assessments, suggesting the possibility of conceptual clarification in addition to attitudinal improvement following Compassionate Schools attendance.

It also seems possible that the nature of some ARTIC items could encourage extremity in responding among trainees. For instance, participants are asked to choose one of the seven numbers "along the dimension" between two statements, but some of the items could be viewed as categorical in nature (e.g., "I don't have what it takes to help my students" vs. "I have what it takes to help my students") and the most "trauma informed" choice is always at a pole. Since the numbers between the extremes are not labeled, it would be interesting to know how participants conceptualized these intermediate options (for instance, what does a "4" mean, exactly, in the example above). In the ARTIC instructions, the sample respondent chose a " 2 " for an item with the following poles: "Ice cream is delicious" and "Ice cream is disgusting." This explanation follows: "In this SAMPLE ITEM, the respondent is reporting that he/she 
believes that ice cream is much more delicious than disgusting." It seems possible, though, that a person might not characterize her attitude in this fashionperhaps people who think ice cream is delicious don't think it's more delicious than it is disgusting... they just don't think it's disgusting at all.

Similarly, one probably would not say that "I have what it takes much more than I don't have what it takes," or "I have what it takes and I don't have what it takes in equal amounts" or "I neither have what it takes nor not have what it takes." Further, some items feature statements that do not appear to represent the poles of any one dimension. For instance, "Students have had to learn to trick or mislead others to get their needs met" vs. "Students are manipulative so you need to always question what they say"; "Students' learning and behavior problems are rooted in their behavioral or mental health condition" vs. "Students' learning and behavior problems are rooted in their history of difficult life events." It seems possible for a participant to believe that students are manipulative because they have had to become so, and that difficult life events are a primary cause of the mental health conditions disrupting the classroom. Does an intermediate rating mean that one agrees completely with both, partially with both, or with neither? Again, it makes one wonder if the poles of such items represent the most attractive response choices, independent of one's attitudes, particularly after a participant has undergone trauma-informed training and feels motivated to respond optimally.

Third, there were a number of methodological limitations. As both studies were considered preliminary, neither employed a control group. In Study 1, a singlegroup, retrospective design was deemed appropriate because of the nature of our primary research question (i.e., how did participants respond to the training?). Due to practical limitations, there was no long-term follow-up assessment in Study 2. It seems plausible (and likely) that attitudinal change over the course of three days was indeed the result of training in the interim, but other explanations for pre-post differences cannot be ruled out (e.g., simple repetition effects). Therefore, although participants reported long-term changes in Study 1 , it is not known whether the ARTIC gains observed in Study 2 will persist over time (notably, Baker and colleagues (Baker et al. 2016) reported strong test-retest reliabilities for the ARTIC over a longer period (e.g., $M=134$ days, $S D=32$ ), particularly for the overall scale). Future studies should fully randomize to carefully selected comparison conditions and conduct longterm follow-up assessments in order to examine rigorously whether trauma-based education is indeed valuable in light of its stated goals, and, if so, if it is uniquely valuable. Eventually, the possibility of dismantling studies should also be considered. For instance, is every component of the multidimensional 3-day training necessary for maximal impact, or are some aspects demonstrably more important than others? (Notably, in our own Study 1, a half-day training was enough to engender reports of a positive, enduring response.) Could certain features be omitted with no discernible effect on outcomes? Which activities are most predictive of behavior change? Which information? Future investigations should involve data collection relevant to the improvement/optimization of the paradigm, as opposed to the mere evaluation of its impact.

Fourth, both studies relied entirely on questionnaire responses. The ARTIC is not only self-report, but is primarily a measure of attitudes (as opposed to behaviors). This puts any resulting scores at some remove from the real-world activities of educators and the educational environments they construct. Study 1 included 2 questions (one dichotomous, one narrative) regarding behavior change, but these were also self-report and consequently susceptible to the array of concerns attending that form of data collection. Of course, establishing perceptions of cognitive, attitudinal, and behavioral change in response to training is an important initial step, but future studies should attempt to tie these effects to changes in the real-world behavior of educators, and to link those changes to improvements in objective student outcomes. These last, of course, will provide the ultimate criteria of success.

With these caveats in mind, it is encouraging that the results from this preliminary investigation align with CPTC perceptions of training impact, and that they provide empirical evidence consistent with the Compassionate Schools model as a whole. Taken with the vast literature on ACEs and detailed reports from comparable initiatives, our findings support the continued evaluation of the Compassionate Schools paradigm as a promising tool for ameliorating the destructive impact of childhood trauma. They also suggest the potential value of the ARTIC as a sensitive measure of trauma-informed attitudinal change.

\section{Compliance with Ethical Standards}

Disclosure of Interest On behalf of all authors, the corresponding author states that there is no conflict of interest. However, the corresponding author and 2nd author are associated with the Training Center.

Ethical Standards and Informed Consent the University of South Carolina Institutional Review Board (USC IRB) has determined that the referenced research study is not subject to the Protection of Human Subject Regulations 


\section{Appendix 1}

\section{Compassionate Schools Training}

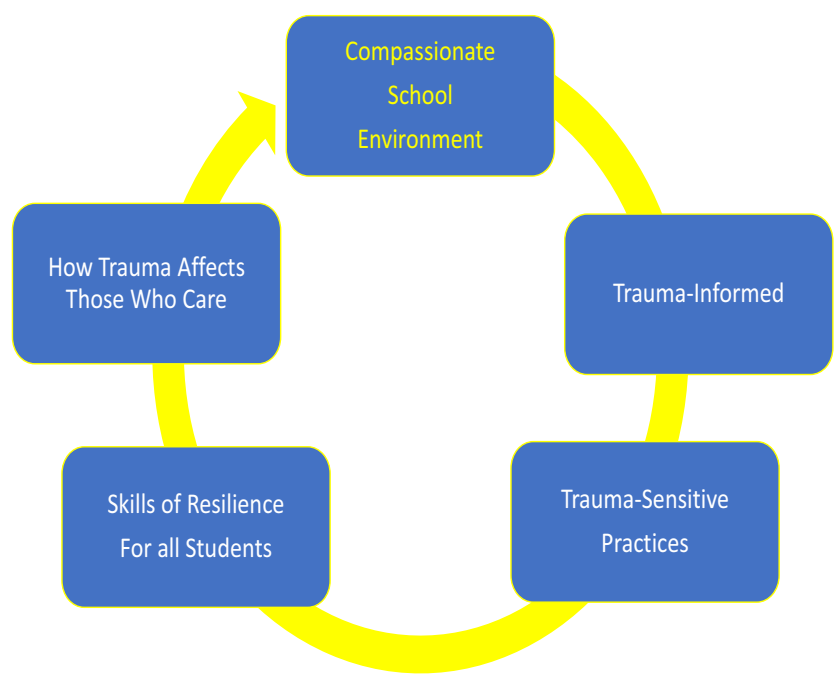

Fig. 1 Trauma-Informed Training Model

\section{Summary of Core Training Modules for Educators}

\section{Trauma Informed}

- Presentation of the ACE study and effects of toxic stress.

- Experiential activity in a mock house with a case example. The house is staged with signs of abuse and significant family issues.

- An interactive brain development activity that demonstrates the impact of toxic stress on early brain development.

- Presentation of signs of abuse and case examples.

- Presentation on mandated reporting and legal responsibility to report.

- Presentation on how to handle disclosures from children.

- View the documentary "Paper Tigers" and discuss Compassionate Schools initiative.

\section{Trauma-Sensitive Practices}

- Recognize disruptive behaviors are a response to stress and learn how to intervene early.

- Introduce techniques to help with stress management and self-regulation.
- Evaluate necessary environmental change to reduce overstimulation and create calming spaces.

- Examine policies and implement changes related to discipline practices and suspensions.

- Recognize and teach methods to manage triggers.

\section{Skills of Resilience for all Students}

- Develop practices that build relationships.

- Develop methods to build confidence and self-efficacy.

- Discuss issues of race, equity and inclusion.

\section{How Trauma Affects Educators and Teach Self Care Strategies}

- Presentation on compassion fatigue, vicarious trauma and burnout. Presentation of self-care strategies, including the development of healthy boundaries.

\section{Appendix 2}

Examples of Narrative Responses

1. "Have you experienced a change in your thinking or mindset following Compassionate Schools training? (Yes/No) If yes, please describe"

a. Knowledge/Cognitive Change

"Change in thinking about how early trauma impact learners."

"Being more mindful of the circumstances that our students live with on a daily basis."

"'What happened to you' instead of 'what is wrong with you' has shifted how I think."

"I know warning signs and red flags to pay attention to."

b. Emotional Change

"I have become more compassionate with students who are going through negative situations in their homes."

"You have to be more understanding of some of the situations students may be experiencing in their home environments."

c. Behavioral Change

"I have slowed down my reaction time to certain situations in order to stop and consider possible ACEs that might be involved." 
"The way I approach and handle student behavior issues."

d. Need for Dissemination

"We need to make our teachers more aware."

"It has made me aware of what training we need to offer our staff."

2. "Have you made any changes (in behavior, practice, or procedure) in response to your Compassionate Schools training? (Yes/No) If yes, please describe"

a. Relationship Building Behaviors

"I have bonded more closely with my students."

"I am more aware of making sure I offer myself as a "safe place" to come and talk."

b. Changes in Practice

"I've been traing to incorporate the mindfulness information we learned into my classroom guidance lessons."

"I immediately implemented a "safe" zone in my classroom."

"Incorporation of breathing exercises to calm students. Incorporation of writing exercises for students who have been sent to the office."

"I use a cool down/wait time prior to speaking with students."

c. Language Changes

"The training helped to give me the vocabulary to help teachers understand trauma in students."

"My verbage has changed when talking to students."

d. Emotional Changes

"I have become more sympathetic as well as empathetic." "More empathy towards some students."

e. Knowledge/Cognitive Changes

"Understanding of the importance of knowning students' ACEs scores and how these experiences may be impacting their learning experiences."

"Understanding that attitudes of students and parents may be caused by ACEs."

f. Changes in Awareness
"Watching for signs of not enough sleep, healthy face and color, grooming and dress."

"I am able to immediately see when a child is reacting to an ACE."

3. "What are the most important things you learned in your Compassionate Schools training (if any)?"

a. Warning Signs of Maltreatment

"Signs to look for in children who are abused."

"How to identify potential problems."

b. Trauma-Informed Skills

"Safe zones... and breathing."

"How to help those who have dealt with traumatic events."

c. Resilience and Relationships

"Build relationships."

"One person can be the "turn around" person for that child and make a lifetime of difference!"

d. ACEs/Trauma Impact

"ACEs - scores and information."

"I was amazed at how ACEs impact brain growth."

"Gave me a better understanding of where our students live and the life conditions they face on a daily basis."

e. Available Resources

"I was not aware of the range of services or support available."

"I better understand the role of DSS and Sheriff's investigators...Although the system has its broken places, I believe that there are options that are available to protect our children."

4. "Which aspects of Compassionate Schools would you like to see implemented at your school?"

a. Parental Involvement

"I'd like for parents to be educated on better ways to rear their children."

"Parent involvement."

b. School/District-Wide Education 
"I would love for my entire staff to be able to have the entire 3-day training."

"Teach this class to every faculty/staff member in the district."

c. Experiential Training

"Teachers should see the mock house."

"I thought the mock house was an awesome thing to see."

\section{d. Disciplinary Changes}

"Modifications to discipline policy, more communication with counselors when discipline infractions occur." "Training in handling student behaviors and outbursts and their connection to ACEs."

e. Resilience Building

"I think helping students build up resiliency would be extremely important."

"I like the part where students are told daily that they are worthy."

f. Already Implemented

"We have implemented this program."

"We have a Compassion School, even before we implemented the training."

g. All

"All of it."

"All."

h. Other

"On-site doctors and medical professionals to help our students."

"Awareness was the most helpful piece of information received."

5. "If there are barriers to implementation, please describe"

a. Time

"There is little time for teachers and support staff to really get to know the student needs due to the "herding effect" of the day."

"School-wide training would be helpful; however, time constraints do not make it feasible."

b. Money
"Our largest barrier is continued funding..."

c. Culture

"I feel that there continues to be a culture and philosophy of "spare the rod" and "spoil" among staff."

d. Support/Buy-In

"Buy-in."

"For administration/counselors to support a more compassionate approach to behaviors."

e. Other

"I do not know as I am not in administration."

6. "What suggestions do you have for improving the training?"

a. None

"None."

"I think you should keep it as is."

b. General Positivity

"Keep up the great work."

"This was the best training I've ever attended."

c. Dissemination

"The more people reached in training the better!"

"My main concern is that we continue the effort to increase the number of educators, community service providers and parents who become aware of the mission of the compassionate schools initiative."

d. Follow-up Trainings

"More intense training in the future as well as refreshers."

e. Technical Suggestions

"Go through the house earlier in the day."

"I would suggest more group or team activities during the day."

f. More Practical Applications

"First steps checklist for schools to help implement the program."

"More hands-on examples of strategies teachers can use." 


\section{References}

Baker, C. N., Brown, S. M., Wilcox, P. D., Overstreet, S., \& Arora, P. (2016). Development and psychometric evaluation of the attitudes related to trauma-informed care (ARTIC) scale. School Mental Health, 8, 61-76.

Bosquet Enlow, M., Egeland, B., Blood, E., Wright, R. O., \& Wright, R. J. (2012). Interpersonal trauma exposure and cognitive development in children to age 8 years: A longitudinal study. Journal of Epidemiology and Community Health, 66, $1005-1010$.

Bronfenbrenner, U. (1979). The ecology of human development: Experiments by nature and design. Cambridge, Massachusetts: Harvard University Press.

Chan, Y.-C., \& Yeung, J. W. K. (2009). Children living with violence within the family and its sequel: A meta-analysis from 1995 to 2006. Aggression and Violent Behavior, 14, 313-322.

Clark, D. B., Thatcher, D. L., \& Martin, C. S. (2010). Child abuse and other traumatic experiences, alcohol use disorders and health problems in adolescence and young adulthood. Journal of Pediatric Psychology, 35, 499-510.

Cole, S. F., O'Brien, J. G., Gadd, M. G., Ristuccia, J., Wallace, D. L., \& Gregory, M. (2005). Helping traumatized students learn: Supportive school environments for children traumatized by family violence. Boston, MA: Massachusetts Advocates for Children.

Cook, A., Spinazzola, J., Ford, J., Lanktree, C., Blaustein, M., Cloitre, M., DeRosa, R., Hubbard, R., Kagan, R., Liautaud, J., Mallah, K., Olafson, E., \& van der Kolk, B. (2005). Complex trauma in children and adolescents. Psychiatric Annals, 35, 390-398.

Copeland, W. E., Keeler, G., Angold, A., \& Costello, E. J. (2007). Traumatic events and posttraumatic stress in childhood. Archives of General Psychiatry, 64, 577-584.

Delaney-Black, V., Covington, C., Odnersma, S. J., NordstromKlee, B., Templin, T., Ager, J., Janisse, J., \& Sokol, R. J. (2002). Violence exposure, trauma, and IQ and/or reading deficits among urban children. Archives of Pediatric and Adolescent Medicine, 156, 280-285.

Felitti, V. J., \& Anda, R. F. (2010). The relationship of adverse childhood experience to adult medical disease, psychiatric disorders and sexual behavior: Implications for healthcare. In R. Lanius \& E. Vermetten (Eds.), The impact of early life trauma on health and disease: The hidden epidemic. Cambridge: Cambridge University Press.

Felitti, V. J., Anda, R. F., Nordenberg, D., Williamson, D. F., Spitz, A. M., Edwards, V., Koss, M. P., \& Marks, J. S. (1998). Relationship of childhood abuse and household dysfunction to many of the leading causes of death in adults: The adverse childhood experiences (ACE) study. American Journal of Preventive Medicine, 14, 245-258.

Ford, J. D., Elhai, J. D., Connor, D. F., \& Frueh, B. C. (2010). Polyvictimization and risk of posttraumatic, depressive, and substance use disorders and involvement in delinquency in a national samply of adolescents. Journal of Adolescent Health, 46, 545-552.

Greenwald, R. (2002). The role of trauma in conduct disorder. Journal of Aggression, Maltreatment, and Trauma, 6, 5-23.

Grogger, J. (1997). Local violence and educational attainment. The Journal of Human Resources, 32, 659-682.
Hertel, R., Frausto, L., \& Harrington, R. (2009). The compassionate schools pilot project report. Olympia, WA: Office of the Superintendent of Public Instruction.

Hurt, H., Malmud, E., Brodsky, N. L., \& Giannetta, J. (2001). Exposure to violence: Psychological and academic correlates in child witnesses. Archives of Pediatrics and Adolescent Medicine, 155, 1351-1356.

Kalmakis, K. A., \& Chandler, G. E. (2014). Adverse childhood experiences: Towards a clear conceptual meaning. Journal of Advanced Nursing, 70, 1489-1501.

Kalmakis, K. A., \& Chandler, G. E. (2015). Health consequences of adverse childhood experiences: A systematic review. Journal of the American Association of Nurse Practitioners, 27, 457-465.

Kilpatrick, D. G., Acierno, R., Suanders, B., Resnick, H. S., Best, C. L., \& Schnurr, P. P. (2000). Risk factors for adolescent substance abuse and dependence: Data from a national sample. Journal of Consulting and Clinical Psychology, 68, 1930.

Ko, S. J., Ford, J. D., Kassam-Adams, N., Berkowitz, S. J., Wilson, C., Wong, M., Bryner, M. J., \& Layne, C. M. (2008). Creating traumainformed systems: Child welfare, education, first responders, health care, juvenile justice. Professional Psychology: Research and Practice, 39, 396-404.

Luke, N., \& Coyne, S. M. (2008). Fostering self-esteem: Exploring adult recollections on the influence of foster parents. Child \& Family Social Work, 13, 402-410.

McLaughlin, K. A., Koenen, K. C., Hill, E. D., Petukhova, M., Sampson, N. A., Zaslavsky, A. M., \& Kessler, R. C. (2013). Trauma exposure and posttraumatic stress disorder in a national sample of adolescents. Journal of the American Academy of Child and Adolescent Psychiatry, 52, 815-830.

Ruchkin, V., Henrich, C. C., Jones, S. M., Vermeiren, R., \& SchwabStone, M. (2007). Violence exposure and psychopathology in urban youth: The mediating role of posttraumatic stress. Journal of Abnormal Child Psychology, 35, 578-593.

Shipman, K., Edwards, A., Brown, A., Swisher, L., \& Jennings, E. (2005). Managing emotion in a maltreating context: A pilot study examining child neglect. Child Abuse and Neglect, 29, 1015-1029.

Shipman, K., Zeman, J., Penza, S., \& Champion, K. (2000). Emotion management skills in sexually maltreated and nonmaltreated girls: A developmental psychology perspective. Development and Psychopathology, 12, 47-62.

Shonk, S. M., \& Cicchetti, D. (2001). Maltreatment, competency deficits, and risk for academic and behavioral maladjustment. Developmental Psychology, 37, 3-17.

Stallard, P. (2006). Psychological interventions for post-traumatic reactions in children and young people: A review of randomised controlled trials. Clinical Psychology Review, 26, 895-911.

Wolpow, R., Johnson, M. M., Hertel, R., \& Kincaid, S. O. (2009). Compassionate schools: The heart of teaching and learning. http:// www.k12.wa.us/CompassionateSchools/Resources.aspx. Accessed date July 2014

Publisher's Note Springer Nature remains neutral with regard to jurisdictional claims in published maps and institutional affiliations. 